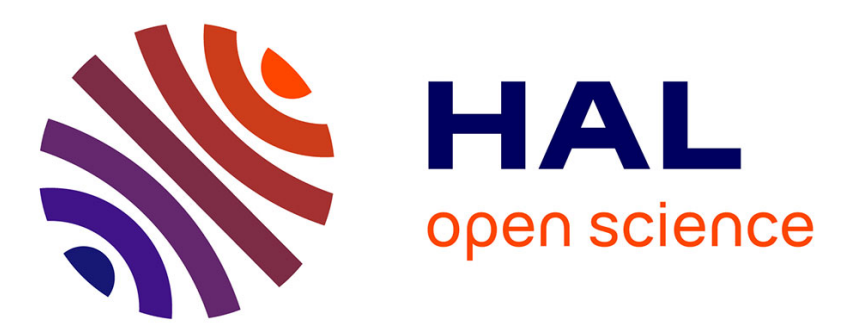

\title{
A System to Assess Students' Competence That Re-uses a Pencil and Paper Tool
}

Stéphanie Jean

\section{To cite this version:}

Stéphanie Jean. A System to Assess Students' Competence That Re-uses a Pencil and Paper Tool. Doctorial Consortium User Modeling 99, 1999, Banff, Canada. pp.337 - 338, 10.1007/978-3-70912490-1_42. hal-01575856

\section{HAL Id: hal-01575856 https://hal.science/hal-01575856}

Submitted on 23 Aug 2017

HAL is a multi-disciplinary open access archive for the deposit and dissemination of scientific research documents, whether they are published or not. The documents may come from teaching and research institutions in France or abroad, or from public or private research centers.
L'archive ouverte pluridisciplinaire HAL, est destinée au dépôt et à la diffusion de documents scientifiques de niveau recherche, publiés ou non, émanant des établissements d'enseignement et de recherche français ou étrangers, des laboratoires publics ou privés. 


\title{
A System to Assess Students' Competence That Re-uses a Pencil and Paper Tool
}

\author{
Stéphanie Jean \\ Department of Computer Science, Université du Maine, France
}

\begin{abstract}
PÉPITE is a multidisciplinary project in computer science and didactics for mathematics. It aims to develop a computerized environment able to model the reasoning process of 15 year-old students in elementary algebra. This work is based on a didactical analysis whose result is a validated pencil and paper diagnosis tool. The aim of the PÉPITE project is to automate this tool.
\end{abstract}

\section{Basis of the project}

We propose an approach of assessment that re-uses a validated pencil and paper diagnosis tool built by educational researchers of the project (Grugeon, 1997). This tool combines a set of pencil and paper tasks with a diagnosis matrix linking questions and dimensions of analysis. This very fine description of the student's behavior requires a higher level description: the cognitive profiles, which are built by transversal analysis of the diagnosis matrix. These profiles describe students' algebraic competence qualitatively. They can be used by teachers to form groups in classes relying on students' knowledge and not just on marks, or in a Computer Supported Learning Environment proposing activities, advice and explanations adapted to the student's knowledge.

The PÉPITE project aims to automate this pencil and paper diagnosis tool.

\section{The Student Interface}

PÉPITEST offers students an adaptation of the pencil and paper tasks to the computer and collects their answers, with 22 different exercises. The design of the student interface plays a significant role in the quality of the diagnosis. Taking into account $\mathrm{HCI}$ issues and adapting them to the AI-Ed domain ensures us better results in the analysis by allowing students to behave as they usually do and therefore by furnishing more reliable answers. So PÉPITEST proposes several carefully designed tools to replace students' usual pencil and paper tools.

PÉPITEST is now completed. It has been tested with 75 students. The main results are as follows. For each question of the test, we have found every kind of answer proposed in the model of algebraic competence: PÉPITEST does not reduce the range of the students' productions. Even if students had difficulties in producing algebraic expressions, PÉPITEST didn't prevent students from writing them. Thus it shows the test's completeness in relation with the model of competence.

Educational researchers can fill in the diagnosis matrix from students' answers to PÉPITEST problems. The teacher of the class could thus confirm the manually obtained profiles. 


\section{The Diagnosis}

PÉPIDIAG interprets and codes students' productions, from the data furnished by PÉPITEST. The difficulty in establishing this diagnosis comes from the variety of exercises and from the variety of students' answers. Each question corresponds to a set of answers usually given by students (this is the result of the didactical research) which corresponds to a code in the diagnosis matrix. The system has to interpret the students' answers to associate them with the right code. This association is quite easy to do with closed questions but can be very difficult with totally open questions where the students mix natural language and mathematics.

A first prototype of PÉPIDIAG already exists. We have obtained these initial results: PÉPIDIAG is able to analyze each multiple-choice answer and every simple algebraic expression answer automatically. We can analyze 75 percent of the students' answers to PÉPITEST problems, partially automating the diagnosis.

We ran PÉPIDIAG on every student answer in our corpus and the system filled the diagnosis matrixes. In order to correlate this partial diagnosis with human assessment, we chose 5 students with different levels of competence and we asked an expert to manually fill in the diagnosis matrix. PÉPIDIAG and the human assessor were quite in agreement.

PÉPIDIAG has now to be fully developed to analyze all the questions in order to obtain full profiles.

\section{The Profiles}

PÉPIPROFIL, the teacher interface, establishes the students' profiles from the filled matrix by transversal analysis (which corresponds to an algorithm) and presents them to the users (teachers or researchers). PÉPIPROFIL is completed. In our evaluation of PÉPIPROFIL we obtained two main results: With a manually filled matrix, PÉPIPROFIL computes the same profile as a teacher does. From the partial matrixes yet filled by the system, PÉPIPROFIL builds partial profiles that are confirmed by the teachers. Tests are planned for the presentation of the profiles to the teachers.

\section{Conclusion}

The three modules of PÉPITE are now completed to a large extent. Our validation criteria are clearly defined: Validating PÉPITEST consists of verifying that we obtain equivalent answers to the pencil and paper test and also that data obtained from the software allows us to build profiles equivalent to the pencil and paper profiles. We evaluate PÉPIDIAG and PÉPIPROFIL by comparing the automatic profiles to human assessors' ones.

From the beginning, we integrated teachers and educational researchers in our design team. This multidisciplinary and user-centered approach allows us to propose a test adapted to students (producing more reliable data) and to build profiles really adapted to teachers' needs.

\section{References}

Grugeon, B., (1997). Design and Using of a Multidimensional Structure of Analysis in Elementary Algebra, In Recherches en Didactique des Mathématiques 17(2): 167-210. (In French) 